\title{
PELATIHAN MANAJEMEN PENGUASAAN KELAS DAN PEMBUATAN BAHAN AJAR BAGI TENAGA PENGAJAR SUKARELA TAMAN BELAJAR KREATIF MEKARSARI
}

\author{
${ }^{1}$ Denok Sunasi, ${ }^{2}$ Gatot Kusjono, ${ }^{3}$ Irwan Nuryana \\ 1,2 Dosen Fakultas Ekonomi Universitas Pamulang \\ ${ }^{3}$ Mahasiswa Program Studi Manajemen Universitas Pamulang \\ Email : $\underline{\text { denoksunarsi@gmail.com }}$
}

\begin{abstract}
ABSTRAK
Kebutuhan akan pendidikan saat ini sangatlah tinggi, percepatan teknologi informasi sangat pesat para pelajar dituntut untuk dapat menguasai apasaja yang menjadi tuntutan perkembangan jaman. Namun lain halnya dengan masyarakat desa yang mengalami keterbatasan, sarana pendidikan diluar sekolah masih merupakan barang mewah yang sangat sulit untuk dipenuhi. Para pemuda Desa mekarsari tergerak untuk membangun sebuah komunitas belajar yang dikhususkan bagi pelajar yang masih aktif sekolah maupun yang sudah putus sekolah. Tujuan kegiatan ini adalah untuk memberikan pelatihan manajemen kelas dan pembuatan bahan ajar bagi tenaga pengajar sukarela Taman Belajar Kreatif Mekarsari.

Metode pelaksanaan adalah dengan memberikan pelatihan, teknik learning by doing, pemahaman penguasaan kelas dan pelatihan pembuatan bahan ajar sebagai sarana dalam kegiatan belajar mengajar.

Hasil kegiatan ini adalah para pengajar sukarela mendapatkan pemahaman penguasaan kelas,di praktekan secara langsung serta pembekalan pembuatan bahan ajar sesuai dengan kurikulum pendidikan luar sekolah.
\end{abstract}

\section{Kata Kunci : Manajemen Penguasaan Kelas, Bahan Ajar.}

\section{PENDAHULUAN}

Permasalahan pemenuhan kebutuhan akan pendidikan di Indonesia sangatlah penting, kualitas suatu bangsa di tentukan oleh tingkat pendidikan masyarakatnya, untuk masyarakat di daerah perkotaan dengan pendapatan yang baik, bukan menjadi masalah besar bagi pemenuhan kebutuhan akan pendidikan baik secara formal melalui sekolah-sekolah, maupun secara non formal melalui kursus-kursus dan les di lembaga kursus baik secara tatap muka langsung, maupun menggunakan aplikasi.

Lain halnya dengan masyarakat desa, yang notabene penghasilan keluarga di dapat dari hasil bertani dan berladang, pemenuhan kebutuhan akan pendidikan dirasa sangat sulit, untuk memenuhi kebutuhan pokok sandang pangan dan papan masih tergolong sulit, apalagi pendidikan, sehingga banyak di temukan anak putus sekolah dan orang tua yang buta aksara. 


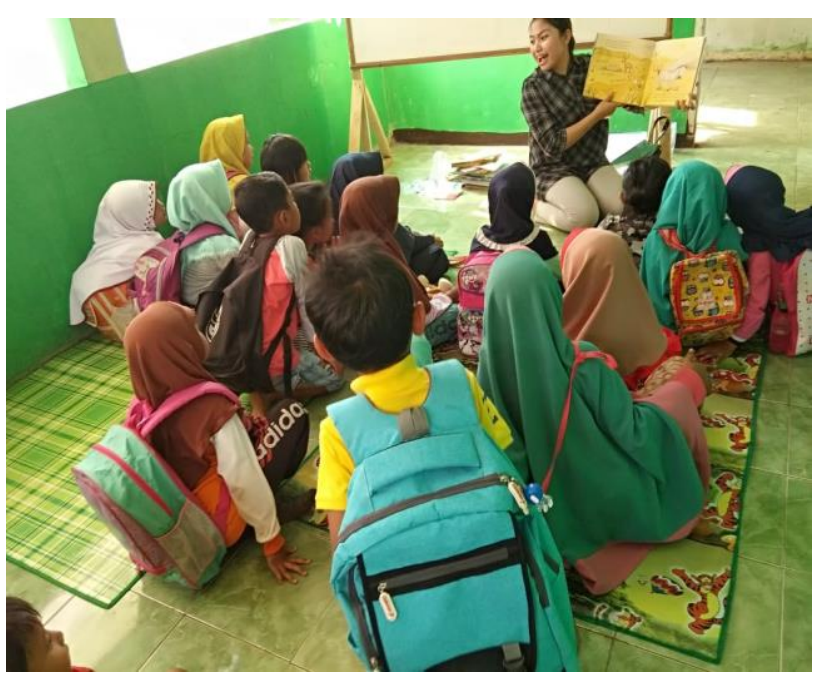

Berdasarkan fenomena tersebut para pemuda Desa Mekarsari Kecamatan Rumpin Kabupaten Bogor menggangas berdirinya komunitas belajar, Taman Belajar Kreatif Mekarsari, yang saat ini masih menumpang di kantor Desa mekarsari.

Seluruh pengajar di Taman Belajar Kreatif Mekarsari adalah para pemuda pemudi desa dibantu oleh beberapa mahasiswa PKL dari Universitas Pamulang, Universitas Islam Negri dan beberapa sukarelawan yang dengan ikhlas mengajar disana tanpa berharap mendapatkan kompensasi.

Berbagai kendala di temukan sementara antusias peserta didik sangat tinggi, mulai dari kuranngnya kecakapan penguasaan kelas, penguasaan teknik mengajar maupun dalam hal pembuatan bahan ajar

\section{METODE PELAKSANAAN KEGIATAN}

Metode pelaksanaan adalah dengan memberikan pelatihan, teknik learning by doing, pemahaman penguasaan kelas dan pelatihan pembuatan bahan ajar sebagai sarana dalam kegiatan belajar mengajar.

Tahap pertama : Dosen pengabdi berkoordinasi dengan mahasiswa dan aparat desa guna mendapatkan ijin menyelenggarakan program pengabdian kepada masyarakat sebagai salah satu tugas dosen dalam mengamalkan tri dharma perguruan tinggi

Tahap kedua : Dosen pengabdi melakukan pembinaan dengan

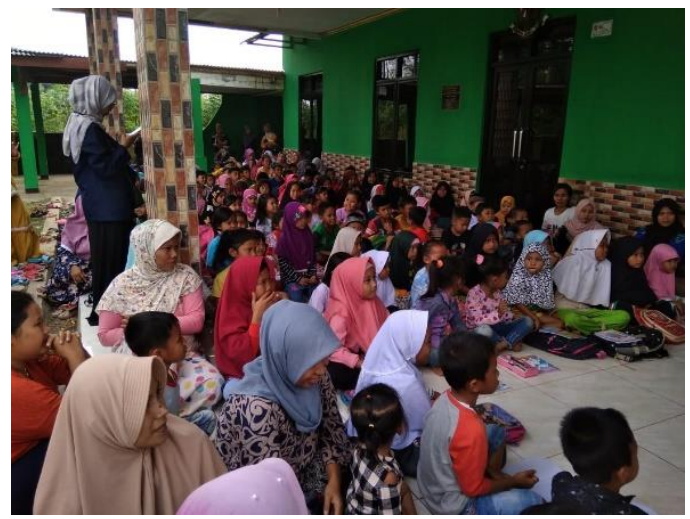
memberikan pelatihan penguasaan kelas dan pembuatan bahan ajar sesuai dengan kurikulum pendidikan luar sekolah

Tahap terakhir : Dosen pengabdi mengadakan evaluasi atas kegiatan yang telah dilakukan

Kegiatan diadakan di kantor Desa Mekarsari. Kecamatan Gunung Sindur. Kabupaten Bogor. Jawa Barat.

Waktu pelaksanaan selama satu minggu mulai tanggal 22 sampai dengan 28 April 2019. 


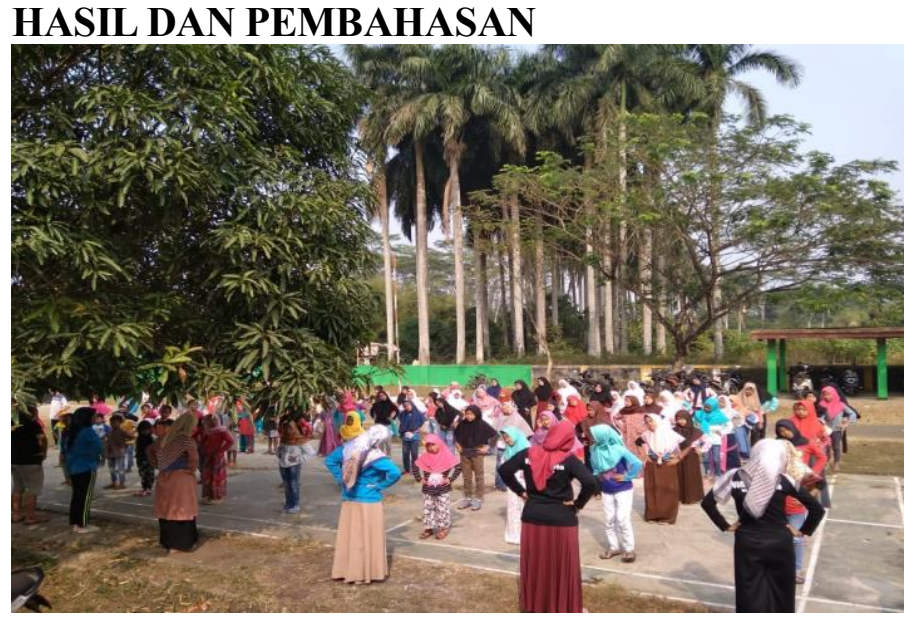

Memperoleh
yang
pendidikan ran
berkualitas merupa-kan hak
bagi seluruh warga negara
Indonesia, sebagai warga
negara Indonesia, karena
sesuai cita-cita luhur
bangsa Indonesia dalam
Pembuka-an UUD 1945
alinia keempat menyatakan
"untuk membentuk suatu
pemerintah negara Indone-

sia yang melindungi segenap bangsa Indonesia dan seluruh tumpah darah Indonesia dan untuk memajukan kesejahteraan umum, mencerdaskan kehidupan bangsa, dan ikut melaksanakan ketertiban dunia yang berdasarkan kemerdekaan, perdamaian abadi dan keadilan sosial, maka disusunlah kemerdekaan kebangsaan Indonesia itu dalam suatu Undang-Undang Dasar negara Indonesia”.

Berdasarkan isi dari pembukaan UUD 1945 tersebut, kualitas pendidikan di Indonesia harus selalu ditingkatkan. Karena melalui pendidikan yang berkualitas akan terbentuk generasi yang berkualitas pula. Pendidikan ini diperlukan untuk mempersiapan generasi yang "melek pengetahuan" dan memiliki karakter dan budi pekerti yang mencerminkan kepribadian bangsa Indonesia. Selain itu, melalui proses pendidikan yang berkualitas peserta didik selain memiliki pengetahuan dan keterampilan sesuai keahlian yang bidang yang dikuasainya juga dapat menerapkan dalam kehidupan sehari-hari.

Akan tetapi, kualitas pendidikan saat ini belum optimal dalam hal memberikan pelayanan pendidikan yang sepadan untuk peserta didik yang berada di daerah perkotaan dan pedesaan. Pendidikan belum optimal meningkatkan potensi yang dimiliki peserta didik. Di perkotaan pendidikan lebih maju dibandingkan di pedesaan.

Tingkat pendidikan juga sangat berpengaruh dalam dunia kerja, terutama pada era modern ini untuk mencari pekerjaan tidaklah mudah karena yang berpendidikan tinggi saja masih banyak yang menganggur atau

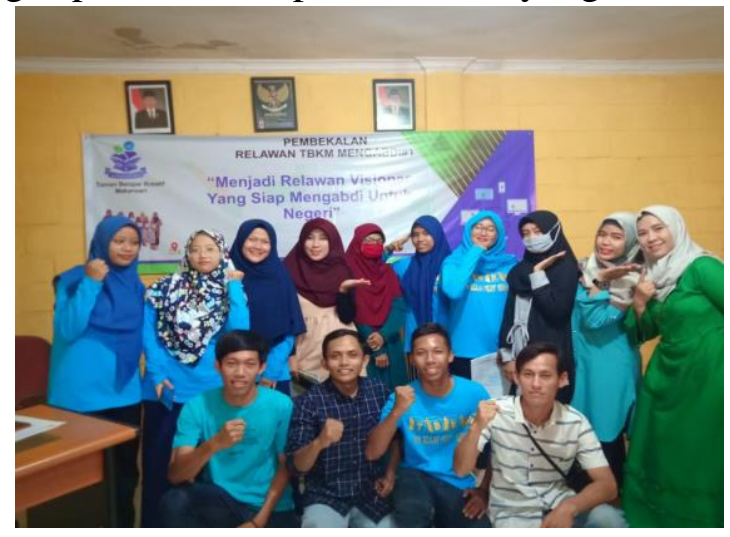
disebut dengan istilah penggangguran terdidik. Di daerah pedesaan, jumlah angkatan kerja yang tidak tamat SD, SMP, dan SMA di pedesaan akan terus meningkat karena angkatan kerja yang tidak tamat SD, SMP, dan SMA di pedesaan akan terus meningkat karena infrastruktur dan minimnya kualitas pendidikan yang kemudian membuat jumlah angkatan kerja meningkat. 
Dengan adanya taman belajar kreatif mekarsari adalah salah satu cara membantu meningkatkan kualitas pendidikan, kualitas sumber daya manusia terutama di wilayah pedesaan.

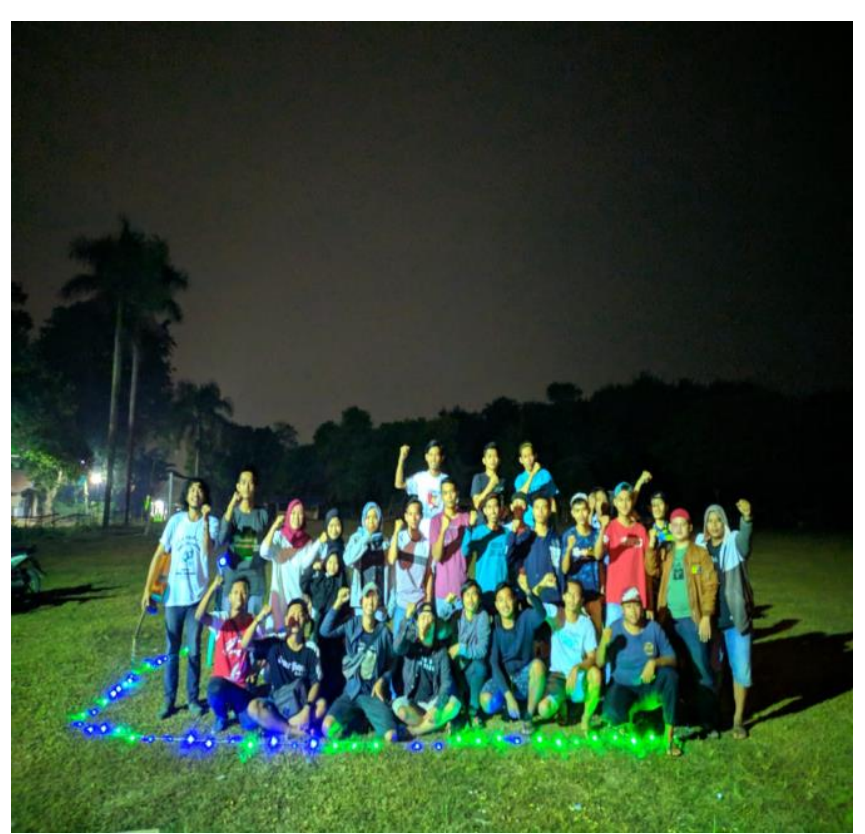

\section{KESIMPULAN DAN SARAN}

Hasil kegiatan ini adalah para pengajar sukarela mendapatkan pemahaman penguasaan kelas,di praktekan secara langsung serta pembekalan pembuatan bahan ajar sesuai dengan kurikulum pendidikan luar sekolah.

Disarankan kepada tenaga pengajar sukarela untuk lebih kreatif lagi dalam membuat bahan ajar atau media pembelajaran agar siswa dapat semangat mengikuti proses belajar mengajar

\section{DAFTAR PUSTAKA}

Hamalik, Oemar. 2008. “Kurikulum dan Pembelajaran”, Cet. 7, PT. Bumi Aksara, Jakarta.

Kusjono, G. (2013). "Hubungan Kompetensi Dan Motivasi Kerja Dengan Kepuasan Kerja Pendidik Studi Kasus Di Pusat Pendidikan Cikal Harapan Bumi Serpong Damai-Kota Tangerang Selatan". Kreatif, Jurnal Ilmiah Prodi Manajemen Universitas pamulang, 1(1), 129-154.

Sunarsi, D., \& Asmalah, L. (2018). "Pelatihan Manajemen Pengembangan Diri Bagi Penerima Beasiswa RZIS UGM Dan Dompet Shalahuddin Jogjakarta”. Jurnal Pengabdian Dharma Laksana, 1(1).

Sunarsi, D. (2018). "Analisis Motivasi Kerja Tenaga Pendidik Sukarela Pada Pusat Kegiatan Belajar Masyarakat (PKBM) Bimasda Kota Tangerang Selatan”. Kreatif: Jurnal Ilmiah Prodi Manajemen Universitas Pamulang, 6(2), 53-65. 